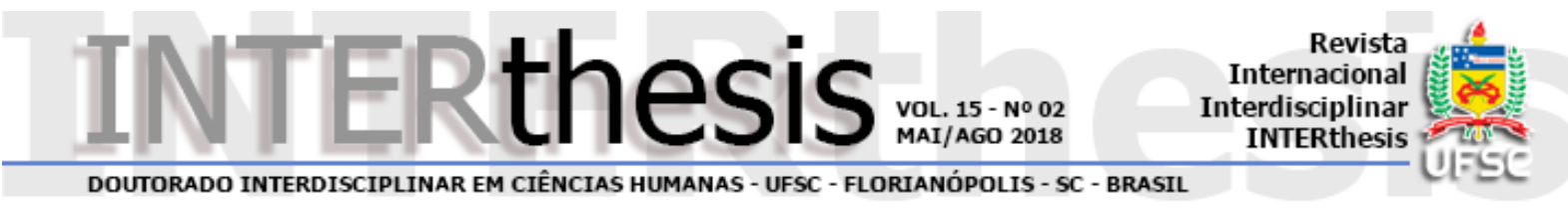

\title{
DISCUSSÕES DE GÊNERO E FEMINILIDADES NA ESCOLA CONTEMPORÂNEA
}

\author{
Melanie Laura Mariano da Penha Silva ${ }^{1}$ \\ Maria Aparecida Tenório Salvador da Costa ${ }^{2}$
}

\section{Resumo:}

Diante dos avanços conseguidos pela atuação dos estudos e movimentos feministas e pelos estudos de gênero, deslocaram-se alguns entendimentos conservadores sobre ser mulher que possibilitaram a desconstrução de ideias limitantes em relação às subjetividades femininas. Na contemporaneidade constantemente se vê em pauta discussões sobre direitos das mulheres, desconstrução de estereótipos de gênero, luta por equidade de gênero. Assim, é fundamental que novos entendimentos sobre feminilidades ocupem espaços nos currículos escolares visando a uma educação para a equidade de gênero desde a infância. Deste modo, este artigo objetiva problematizar a permanência de padrões sexistas na instituição escolar e o papel da educação formal na desconstrução dos mesmos, possibilitando aos sujeitos novos entendimentos sobre subjetividades femininas e modos de ser mulher que não se limitem aos estereótipos tradicionais. Como forma de compreender a construção de sentidos e significados utilizou-se a Análise de Discurso. Preliminarmente, foram identificados discursos progressistas e conservadores, em relação ao debate de gênero e as questões das mulheres, coexistindo e disputando espaço no ambiente escolar. Ao mesmo tempo, observou-se o potencial de tais discursos no fomento de subjetividades desde a mais tenra idade. Os resultados encontrados evidenciaram, grosso modo: a necessidade de melhorar a formação docente em temas como diversidade e gênero; a falta de preparo de diversos sujeitos do ambiente escolar para lidar com questões de gênero; a importância de debates sobre gênero e feminilidades no espaço escolar como forma de contribuir com a formação cidadã de crianças, das famílias e dos sujeitos que trabalham no ambiente escolar.

Palavras-chaves: Educação. Gênero. Subjetividades. Feminilidades. Escola.

\section{INTRODUÇÃO}

Durante a infância surgem os primeiros questionamentos sobre gênero, sexualidade e os modos de cada um/a ser e estar no mundo. As dúvidas, curiosidades, anseios sobre essas temáticas estão presentes nos diversos ambientes em que a

\footnotetext{
${ }^{1}$ Mestranda do Programa de Pós-Graduação em Educação da Universidade Federal de Pernambuco, Recife, PE, Brasil. E-mail: melmariano.12@gmail.com

2 Doutora em Sociologia pela Universidade Federal de Pernambuco. Professora da Universidade Federal Rural de Pernambuco, Recife, PE. Vice-coordenadora do Programa de Pós-Graduação em Extensão Rural e Desenvolvimento Local em Recife, PE, Brasil. E-mail: aparecidatcosta@hotmail.com
} 
criança circula, um deles é o escolar. Por ser a escola "o espaço para a socialização secundária" (Goméz, 1998, p.54), é também diante da cultura escolar estabelecida e das vivências coletivas e individuais experimentadas durante o período de escolarização, que as identidades são forjadas e abastecidas nos modos de pensar, agir, sentir o mundo e as coisas ao seu redor. Ou seja, esta instituição atua como instância subjetivadora, interpelando os sujeitos e promovendo a construção de significados. Fischer (2002), define a subjetivação como sendo complexos processos de veiculação e de produção de significações, de sentidos, os quais, por sua vez, estão relacionados aos modos de ser, de pensar, de conhecer o mundo, de se relacionar com a vida, que permitirão aos sujeitos construírem-se. A subjetivação é sempre um processo histórico e mutável, que, portanto, está contextualizado a uma época e a um tipo de formação social.

$\mathrm{Na}$ escola, uma das dimensões alcançadas por estes processos de subjetivação incide, pois, na construção de sentidos sobre gênero. Dito isto, o presente artigo se debruça sobre a discussão de padrões sexistas ainda presentes na educação escolar, problematizando os entendimentos que a escola contemporânea tem sobre gênero e, especialmente sobre as subjetividades femininas. Acredita-se que é preciso perscrutar como a escola produz significados sobre gênero junto às crianças, visto que em vários espaços pelos quais transitam, os sujeitos apreendem o que é o feminino, ou o masculino, de forma rígida através de preceitos historicamente imbuídos de aspectos machistas e sexistas, incidindo sobre a construção das identidades de gênero e sendo repassados como valores pela educação familiar e/ou escolar.

A formação do imaginário sobre subjetividades femininas é influenciada pelos discursos e práticas dos sujeitos sociais que integram o contexto escolar, sendo construídos a partir da compreensão que os mesmos têm do que é ser mulher e/ou homem. Ao pretender reformular entendimentos, as concepções de gênero diante de uma perspectiva de equidade, desenvolvem uma visão relacional entre feminino e masculino, superando o binarismo e, sobretudo, a hierarquização das relações entre homens e mulheres, posto que isso acaba por reforçar o sexismo na cultura escolar. Deste modo, sendo a escola um espaço para construção social e pessoal, é preciso formar para a equalização das relações de gênero desde a infância, assim como para o entendimento de que há diversas possibilidades de se performar o gênero, se construir, ser/estar/atuar na sociedade. 


\section{METODOLOGIA}

Para o presente escrito, a pesquisa desenvolvida, repousa sobre a abordagem de caráter qualitativo, que segundo Deslandes (1994, p.22): "se aprofunda no mundo dos significados das ações e relações humanas". Assim sendo, acredita-se que essa seja a abordagem que mais coadunou com os objetivos da investigação. A partir de um estudo de caso em conformidade com o que Becker (1997) dispõe, ao afirmar que em geral o estudo de caso em ciências sociais é voltado para a compreensão de uma organização ou instituição, realizaram-se visitas a uma instituição escolar pública para apreender significados e sentidos relativos à temática estudada.

Em termos da perspectiva teórico-metodológica busca-se com o pósestruturalismo pensar em múltiplas aberturas para explorar os fenômenos aqui discutidos, questionando as construções feitas ao redor deles, visto que conforme Silva (2011), essa perspectiva possibilita compreender o processo de fabricação das verdades sociais. Também da crítica pós estruturalista utiliza-se a noção de discurso, pois ainda conforme Silva (2011), a importância da linguagem é ampliada nesta perspectiva, fazendo com que o discurso seja entendido como algo que extrapola a própria linguagem e dá significado às práticas sociais. Segundo Foucault (2012), o discurso seria um conjunto de enunciados que apoiados em formações discursivas estruturam sistemas de pensamentos e estão sempre perpassados por relações de poder. Os discursos são, pois, para Foucault (2012), enunciados capazes de produzir significações na realidade, porque o discurso relacionaria práticas sociais e linguagem. Partindo deste ponto, acredita-se que na escola estão práticas sociais que produzem saberes sobre gênero os quais precisam ser problematizados. Conforme Fischer (2002), um aparato discursivo é responsável por uma imensa produção de saberes que envolvem uma complexa trama de práticas acompanhadas da produção e da veiculação destes saberes produzidos pelos discursos.

Os sujeitos participantes da pesquisa compuseram dois grupos: sujeitos da escola (uma gestora, duas funcionárias de serviços gerais e uma professora); e sujeitos da família (grupo de seis mulheres composto majoritariamente por mães e com a presença de duas avós). Para a coleta de dados, fez-se utilização de duas técnicas. A primeira foi a entrevista semiestruturada, que de acordo com Deslandes (1994), se assemelha a uma conversa com propósitos bem definidos para obter dados 
referentes a uma realidade. As entrevistas foram realizadas ao longo de uma semana com os sujeitos que trabalhavam no ambiente escolar.

A segunda técnica utilizada foi o grupo focal, que segundo Gatti (2005), consiste na discussão de um tema, a partir da experiência dos participantes, e que, via de regra, envolve algum tipo de atividade coletiva como assistir a um filme, examinar um texto ou debater questões selecionadas esperando que se possa obter diversas compreensões sobre o tema, visto que, o grupo focal tem a possibilidade de fazer emergir certa multiplicidade de pontos de vista e sentimentos. O grupo focal foi desenvolvido com os sujeitos da família. Para a organização deste foi anunciado no momento em que as participantes deixavam suas crianças na escola que ocorreria tal atividade de pesquisa, solicitando a participação das responsáveis. As que se dispuseram a participar foram convidadas para a biblioteca da escola, onde foram apresentadas ao tema da pesquisa e à metodologia da atividade e onde corroboraram sua concordância em apresentar suas opiniões e participar da pesquisa mediante ata.

As participantes assistiram a dois curta metragens: Por ser menina (Plan International Brasil, 2014), que discute algumas condições desiguais, que algumas meninas ainda enfrentam em nosso país, sobretudo no acesso e continuidade aos estudos, e Princess Machine (Golden Box, 2013), anúncio de brinquedos para meninas que iam além de bonecas, maquiagem ou coisas de cor de rosa, como forma de questionar atividades e objetos limitantes oferecidos ao público feminino.

Cabe ressaltar que as questões desencadeadoras em ambas as técnicas discutiam temas como: educação sexual; concepção de papel de homem e de mulher na sociedade; educação de meninas e de meninos; gênero; diversidade sexual; o papel da escola e da família diante das questões de gênero.

Para a realização destas atividades foram respeitados os princípios éticos da pesquisa com seres humanos e as propostas de trabalho foram previamente apresentadas à gestão da escola, sendo posteriormente aprovadas. Como colocado nos Parâmetros Curriculares Nacionais (1997), em seu caderno de Pluralidade Cultural, na temática de orientação sexual, define-se que o trabalho sobre relações de gênero deve servir para combater relações autoritárias, questionar a rigidez de padrões de condutas estabelecidos para homens e mulheres e apontar para a sua transformação. Os resultados destas coletas foram tratados a partir da Análise de Discurso conforme perspectiva referenciada anteriormente. 
Por meio deste delineamento metodológico desenvolveu-se a pesquisa que culminou no presente escrito, e que se encontra na intersecção dos conteúdos e temáticas de gênero com a área de Educação.

\section{EDUCAÇÃO, SUBJETIVAÇÃO E UMA CONVERSA INICIAL SOBRE GÊNERO}

Os ideais educativos, junto com as experiências adquiridas em diferentes momentos e espaços de interação social, exercem influência sobre a construção das subjetividades dos sujeitos, sobre seu modo de ser e estar no mundo, sobre o modo como enxerga o outro e a si mesmo, fomentando, o que se chama de processos de subjetivação (FISCHER, 2002). Estes processos, no contexto do mundo atual, fazem, de acordo com Hall (1997), com que a identidade seja sempre formada e transformada segundo as formas pelas quais somos interpelados pelos sistemas culturais que nos rodeiam, de tal modo que o sujeito pode assumir identidades diferentes em diferentes momentos.

Ainda para Hall (1997), as sociedades do mundo atual, são sociedades de mudança constante e rápida, ocasionadas por fatores como a globalização que acaba agregando diversos valores e vivências para coexistirem num mesmo tecido social. Neste contexto, o sujeito acaba sendo perpassado por discursos produzidos em diversas instâncias, sendo a escola uma delas. A escola ultrapassa a socialização de saberes, se colocando também na produção de sentidos que dizem como devemos conhecer ou reagir a determinados aspectos da vida. As práticas pedagógicas escolares se constituem como dispositivos produtores de imagens, textos, significações que irão ensinar modos de ser e estar.

Considerando que em nossos tempos, como escreveu Foucault, a grande e necessária luta a ser empreendida será aquela que se faz contra tudo aquilo que mais submete nossa subjetividade, entendo que no campo educacional um dos investimentos maiores será justamente indagar sobre, afinal, como cada um de nós participa dos processos de produção de sentidos na nossa sociedade. (FISCHER, 2002, p.8)

A escola, neste sentido, precisa ser vista como lugar da interpelação, no qual saberes serão dirigidos aos sujeitos, mas no qual também os sujeitos irão se envolver na produção de significados sobre estes saberes. Neste contexto, os significantes irão flutuar no espaço escolar e envolver-se em relações de poder geralmente atreladas ao discurso que detêm a hegemonia social em determinado momento. Cabe então perceber que os discursos aparecem na constituição dos saberes estando em 
constante processo de deslizamento e contingência histórica de sentidos. Quase sempre existindo sobre uma espécie de lógica da coexistência, que na realidade, certifica o embate entre diferentes discursividades constituintes do espaço social.

Nessas discursividades também incidem sobre os comportamentos e subjetividades dos sujeitos, os padrões conservadores que podem ser observados como fatores que engessam a aceitação de novas concepções e a incorporação de novos paradigmas em diversas situações sociais, gerando o embate com padrões progressistas. Assim, podem ser engendradas violações aos direitos de homens e mulheres de exercerem suas identidades como as entendem ou desejam e de performar o gênero da forma que mais the seja natural.

Muitas questões conservadoras começaram a ser questionadas inicialmente pelos estudos feministas e por meio do conceito de gênero. Compreende-se que tais questionamentos se tornaram possíveis pois, como dito por Scott (1995), o gênero tornou-se uma categoria de análise histórica que permitia perscrutar a construção social e cultural do feminino e do masculino, atentando para as formas pelas quais os sujeitos se constituíam e eram constituídos, em meio a relações de poder. Piscitelli (2009), informa que o termo foi elaborado inicialmente para desmontar um duplo procedimento de naturalização, mediante o qual as diferenças que se atribuem a homens e mulheres são consideradas inatas, derivadas de distinções naturais, sendo as desigualdades percebidas como resultado dessas diferenças. Ainda, de acordo com a autora, o termo gênero foi assim pensado para referir-se ao caráter cultural das distinções entre homens e mulheres, entre ideias de masculinidade e feminilidade. Este, parece ter sido o entendimento que mais foi apreendido, sobretudo academicamente, no entanto o conceito seguiu sendo reformulado considerando, por exemplo, sua intersecção com outros marcadores como raça, classe, sexualidade, assumindo, inclusive, elementos políticos que melhor fornecessem ferramentas à luta dos sujeitos mulheres e posteriormente de Lésbicas, Gays, Bissexuais, Travestis, transexuais e transgêneros (LGBTs). Por isso, na emergência do conceito de gênero:

\begin{abstract}
Além de situar a mulher social e culturalmente e de fazer distinção entre o conceito de sexo, é colocada ênfase no caráter político das relações entre os sexos e observa-se que os sistemas de significado que produzem noções de diferenças entre homens e mulheres oprime não só as mulheres, como também pessoas que se colocam fora da heterossexualidade. (PISCITELLI, 2009, p.5)
\end{abstract}

Assim, os estudos de gênero avançaram na elaboração do conceito fazendo com que houvesse, além da distinção para com o sexo, o aprofundamento sobre os 
entendimentos das relações de poder que perpassam o gênero. Isto permitiu que fosse compreendido como um sistema que oprime a partir das diferenciações, mas também conforme dito por Piscitelli (2009), como um exemplo do modo pelo qual o poder opera através de estruturas fluídas e múltiplas, posicionando as mulheres em lugares diferentes e em momentos históricos particulares. Permitindo que pessoas individual ou coletivamente possam se opor às estruturas opressivas de gênero.

Portanto, assumindo a já referida perspectiva de Scott (1995) sobre o conceito, falar de gênero é compreender que há relações de poder que o envolvem e que atingem as experiências e o processo formativo dos sujeitos. Isso porque, "o gênero é uma forma primeira de significar as relações de poder." (SCOTT, 1995, p. 91) permeando a vida social. Para Butler (2005, p.29) representação do gênero se constrói "como fenômeno inconstante e contextual, o gênero não denota um ser substantivo, mas um ponto relativo de convergência entre conjuntos específicos de relações, cultural e historicamente convergentes". Além disso, o gênero também envolve perceber as inter-relações entre masculino e feminino atuando nas subjetivações dos sujeitos e muitas vezes escapando da tal composição binária que põe em oposição masculino e feminino. Louro (1997), sinaliza a necessidade de evitarmos a visão binária de gênero considerando que a proposição da desconstrução das dicotomias pode se constituir numa estratégia fértil para o pensamento.

A proposição da desconstrução da dicotomia também alcança o ser mulher, pois não o coloca sob uma fórmula única de feminilidade. Entende-se a categoria das mulheres como ampla e diversificada, o que implica saber que há diferentes necessidades, anseios e representações das mulheres. Há, portanto, diferentes feminilidades que passaram por processos de subjetivação diversos. E por isso, não se limitam aos conceitos estáveis do que é ser menina/mulher que são apreendidos socialmente, os quais são inclusive muitas vezes produzidos na educação formal escolarizada.

O debate sobre gênero tem transitado na sociedade de forma política e social e em diversos espaços. Na esfera da educação, o tema experimenta algumas vezes, cerceamentos quanto à sua abordagem no ambiente escolar. Diferentes estados brasileiros questionaram a legitimidade, bem como a necessidade de discutir questões de gênero na sala de aula, tentando suprimir tais conteúdos de seus Planos Estaduais de Educação, como foi o caso dos estados de Pernambuco e São Paulo no ano de 2015. 
Portanto, apesar da circulação social do termo gênero, entraves como o exemplificado acima fazem com que ao olhar para a escola, ainda se perceba a presença do sexismo nesse espaço educativo, funcionando como mais um dos mecanismos que inibem o educar para o respeito às diferenças e à equalização das relações de gênero, fazendo perpetuar o status quo da segregação entre espaços e universos masculinos e/ou femininos, bem como evitando a superação de discriminações baseadas no gênero, que estão na base de problemas sociais como a homofobia ou a violência contra a mulher.

Uma educação não sexista entende que as diferenças não são limitadoras de fazeres, ao contrário, podem indicar maior colaboração entre homens e mulheres dentro da sociedade ou maior liberdade na vivência do gênero. Por isso, se reitera a necessidade e utilidade do trabalho sobre gênero na escola contemporânea, pois é preciso instituir práticas que combatam a discriminação, bem como formem os sujeitos tendo em vista as mudanças que vêm ocorrendo nas relações de gênero.

\section{DISCUTINDO GÊNERO E FEMINILIDADES NA ESCOLA}

Como sinalizado anteriormente, com o desdobramento dos estudos de gênero e das problematizações acerca do conceito, algumas concepções foram revisitadas a fim de que entendimentos fossem construídos e aprimorados. Diante disso, considerase importante perscrutar as concepções sobre feminilidades e sobre identidades de gênero na escola contemporânea.

As questões sobre feminilidades podem ser exploradas tanto do ponto de vista da desuniversalização do sujeito mulher, quanto da própria radicalização da crítica pós estruturalista ao sujeito estável, unívoco e centrado. Silva (2011), aponta que no pós-estruturalismo o sujeito centrado é encarado como uma invenção histórico-social e que partindo de construtos foucaultianos se assume que não existe sujeito, a não ser como resultado de processos de produção cultural e social marcados por relações de poder. Outro ponto é que essa invenção do sujeito é problemática frente ao gênero, pois evoca sempre o masculino, fazendo com que o homem seja sempre $O$ sujeito e a mulher sempre o outro deste sujeito. Portanto, ao desconstruir a universalidade e o essencialismo do sujeito é preciso primeiramente desconstruir a ideia de que este sujeito é o masculino, fazendo emergir o sujeito mulher. 
No entanto, nas análises sobre este sujeito mulher as problematizações se depararam com a insuficiência desta categoria na representação dos diversos grupos femininos, necessitando assim, da desconstrução do próprio entendimento do sujeito mulher em direção a sua desuniversalização. Portanto, conforme explica Mariano (2005), a desconstrução do sujeito é ao mesmo tempo uma crítica ao sujeito masculino universal e uma crítica ao sujeito denominado mulher. Assumindo, portanto, que as experiências das mulheres são diversificadas e estão imbricadas em marcadores como raça, classe, idade, sexualidade. Conforme Butler (1998), compreendendo que o sujeito é constituído discursivamente, é contingente e político, pode-se procurar pensar então sobre mulheres, femininos, num plural que está envolto em contingências e deslizamentos e por isso, pode curiosamente ainda não abarcar todas as experiências e vivências possíveis de ser mulher. Grosso modo, é diante destas discussões que se pensa em feminilidades.

Refletir sobre a compreensão do conceito de identidade de gênero, também implica recusar a essencialização e universalização sobre identidades. Ainda de acordo com o pensamento de Butler (2005), negando-se a estabilidade do sujeito e assumindo sua construção a partir da linguagem, dos discursos, então se pode compreender que o próprio gênero também o é construído discursivamente. Assim, a identidade de gênero, posiciona-se como o "eu" no gênero. Ela é compreendida por Butler (2005), como algo performativo, ou seja, como os gestos, atos e signos que são feitos em direção a como me enxergo no gênero. No entanto, ainda de acordo com esta autora, a inteligibilidade desta identidade está ligada a uma coerência com o sexo, na qual só é possível que cada identidade de gênero se ligue a seu sexo correspondente, fazendo com que pessoas que fogem a esta coerência imposta, quando compreendem que seu sexo está ligado ao gênero oposto, sejam desumanizadas e expostas a situações de discriminação ou marginalização social, como é o caso de pessoas trans.

Portanto, pensar feminilidades ou pensar as identidades de gênero envolve compreender modos de ser, impostos para feminino ou masculino, bem como experiências que indicam diversas maneiras de se identificar como mulher, homem, ou nenhum dos dois, algo a parte destas concepções. Apesar disso, nem sempre estes entendimentos são aceitos sem embate no social, posto que vão contra o status quo em que as construções sociais feitas acerca do feminino e do masculino se apresentam como algo dado, imprimindo a sensação de que há uma ordem natural a 
ser seguida quando se pensa em diversas questões de gênero. Possivelmente, por essa razão, a pesquisa de campo realizada em uma escola pública apontou que trabalhar a questão de gênero e identidades femininas, ainda, deixa desconfortável boa parte dos sujeitos abordados. Por meio do que foi coletado pôde-se analisar os entendimentos de feminilidades para a instituição escolar e o modo como a educação da instituição convive ou desenvolve essas concepções.

A primeira abordagem diz respeito a uma investigação sobre a separação de universos de meninos e de meninas. Ao serem indagadas sobre haver ou não diferenças entre meninos e meninas, duas funcionárias de serviços gerais, expressaram uma concepção de que há um lugar determinado para o que é do feminino com jeitos e modos próprios de agir, estabelecidos ao longo do tempo pela sociedade. Assim, a "funcionária A" explica que antigamente "as meninas eram muito de sentar, conversar, brincar de boneca, aquelas brincadeiras normais. E correr, brigar, pular, era muito coisa de menino. Mas, hoje em dia não, hoje em dia as meninas estão do mesmo jeito". A "funcionária B" concorda com esta fala e demonstra certa preocupação sobre o comportamento das meninas tentando explicar o que para ela se caracteriza como conflito: "Hoje em dia as meninas querem as brincadeiras dos meninos, querem tomar as atitudes dos meninos e os meninos as atitudes das meninas, aí está existindo certo conflito". E, enfatizando a necessidade da determinação de lugares para menina e para menino, a "funcionária B" conclui: "Eu acredito que isso seja anarquia, por que ninguém sabe mais o que é lugar de menino e menina, brincadeira de menino e menina. Tem menino que procura o seu lugar de menino e tem menina que procura o seu lugar de menina, mas é a minoria".

As funcionárias demonstraram ao defenderem lugares fixos entre os gêneros, entender que a falta de reforço aos papéis pré-determinados não significa liberdade de ação, mas um problema de comportamento (usando o termo anarquia como sinônimo de bagunça). Em seus discursos, ainda predomina a visão angelical e delicada sobre as meninas, disseminada no imaginário social como forma natural de ser mulher. Por outro lado, na visão sobre os meninos repousa a ideia de que é próprio da natureza deles correr mais, bagunçar mais, ser mais atrevido e alegam que por isso fica "mais feio" para as meninas agirem com modos que seriam próprios dos meninos. Esse pensamento é ratificado pela "funcionária A", quando fala do recreio: "as meninas não brincam, elas não sentam, elas não conversam, elas jogam lixo no chão do mesmo jeito que os meninos, elas dão tapas nas costas dos outros. E a gente 
via, que na nossa época, não era assim". A funcionária compreende, portanto, que em função do gênero a cobrança pelo dito "bom comportamento" deve ser maior para as meninas, pois, em caso de indisciplina, ela ressalta que as meninas "acabam sendo mais malvistas por serem meninas, por que a gente tinha aquela ideia de que mulher é um ser mais recatado, mais na sua. E quando você as vê assim, fica até com medo de onde isso vai parar".

Esses depoimentos indicam que não há o entendimento sobre a existência de diferentes feminilidades, mas o reforço do que seria um padrão tradicional e opressivo, que, segundo Carvalho (2009), está apoiado na obediência às normas, na organização e na submissão, exacerbando as diferenças de gênero.

Esses discursos revelam ainda, uma falha educacional perpetuada na delimitação de padrões de gênero, com alguma permissividade que ignorou o mau comportamento infantil, sobretudo masculino (bagunça, agressividade, desrespeito), baseando-se no entendimento de que é próprio da natureza do homem ser mal comportado, rude, violento, pois isso é desejável como sinal de masculinidade. No entanto, quando esse mau comportamento é encontrado nas meninas a sociedade não trata apenas como uma questão de educação comportamental, mas condena essas ações ressaltando a inapropriação delas para meninas e trata de agir para que o padrão de uma feminilidade angelical anteriormente estabelecido seja garantido. Assim, reprime as meninas, ao invés de oferecer soluções educativas para meninos e meninas, visando a não violência, a cordialidade, o respeito ao outro e a si mesmo, reafirmando uma cultura de paz. Este é um exemplo de como a formação discursiva costurou diferentes discursos sobre indisciplina baseados em padrões de comportamento desejáveis para meninos e meninas, culminando num discurso que reforça a desigualdade de gênero onde aparentemente haveria apenas um discurso sobre a correção do que seria considerado mau comportamento.

Em outro momento das entrevistas, com a gestora da escola, ela demonstra, em seu discurso, acreditar que houve uma transformação negativa do comportamento feminino, após as conquistas advindas do feminismo como liberdade sexual, direito a trabalho fora do lar, quando faz a seguinte afirmação: "o que a gente vê hoje são meninas mais agitadas do que os meninos, e agitadas em todos os sentidos, em relação à agressividade, à sexualidade, a tudo". Essa mudança de comportamento, na compreensão da "gestora A", repercutiria negativamente: "Os valores elas não têm. A mulher, agora, não precisa que ninguém a desrespeite, ela mesma se desrespeita". 
E para ilustrar como a mulher desrespeita a si mesma, a entrevistada exemplifica: "a partir do momento em que você escuta certas músicas, faz questão de usar certas roupas por que está na moda, está se desvalorizando. E, a gente tenta mostrar às meninas isso, que elas têm que ter uma postura que imponha respeito".

O discurso da gestora, em questão, revela-se circunscrito a uma visão de mundo que ainda desconhece as questões de gênero e as lutas feministas forjadas nos princípios de equidade, liberdade (inclusive sexual), e ruptura com estruturas machistas, que colocavam/colocam a mulher enquanto responsável pela conquista de seu próprio respeito por meio do que seria socialmente aceito como "um bom comportamento". Segundo essa visão, apenas a "boa moça" aquela que é uma mulher contida, merece ser respeitada na sociedade. Neste depoimento, é possível apontar uma contradição, que se perpetua historicamente em nossa sociedade, a de que o respeito é inerente à condição humana, mas, mesmo assim, socialmente continua atrelado às atitudes merecedoras dele, quando se trata da mulher. Então, além de haver o reforço a padrões servis, dentro de um agir angelical, que seria próprio do feminino, os ideais machistas repassados historicamente, ainda delegam sobre a condição da mulher, que as conquistas são provenientes do bom comportamento.

Conforme citado outrora, foi encontrada coexistência dos discursos, portanto, nem só de discursos tradicionais e limitadores se faz a escola. Uma docente entrevistada acredita que a escola pode fortalecer a luta das mulheres ao evidenciar para as meninas, por exemplo, que hoje a mulher tem um espaço maior na sociedade e tem conquistado autonomia, não estando mais condicionada, apenas ao lar, ao marido e aos filhos. Condições estas que, de acordo com Muchembled (2007), são resultantes justamente da herança da "boa moça" que coloca no casamento, o caminho único imposto socialmente ao feminino, reforçando a formação de uma mulher na lógica da família tradicional para casar-se, ter filhos e dedicar-se exclusivamente ao lar e ao homem.

Para a entrevistada, a escola deve educar as crianças para que elas conheçam as oportunidades que existem, dando-lhes uma educação menos autoritária, mas que também ofereça informação para agirem com responsabilidade diante das escolhas que fizerem. Na visão dessa professora do $5^{\circ}$ ano do ensino fundamental, mesmo com a informação dos dias de hoje deve-se insistir numa educação menos limitadora à atuação feminina, ela se mostra desejosa dessa educação emancipadora desde a infância quando revela: 
Eu gostaria que as meninas hoje fossem educadas de modo diferente de como eu fui educada, por que eu fui educada assim: menina não faz isso, menina não brinca com menino, menina não anda na rua tarde e eu não sabia nem por quê. As coisas eram ditas e tinham que ser aceitas. [...] A mulher tinha que fazer as coisas para o homem. No meu tempo o homem trabalhava fora e a mulher cuidava da casa, hoje não, a mulher tem que estudar, ter seu emprego, sua formatura e o casal fazer as coisas. [...]. Eu tento mostrar que a vida deles hoje está muito igual, não existe mais aquilo de por trás de um grande homem está uma grande mulher, eu acho que está ao lado. Eu trato as minhas alunas do mesmo jeito que os meninos.

O discurso da professora expressa a compreensão sobre a necessidade de uma educação que discuta gênero, a fim de desestimular desigualdades e, principalmente, evidenciar as conquistas das mulheres como forma de evitar a negação de direitos e oportunidades. Trabalhar com gênero não significa conferir maior respeito a um ou a outro, mas equalizar uma educação e diminuir as desigualdades que existem. Discutir gênero, enquanto importante fator constitutivo da identidade de mulheres e de homens é útil em vários aspectos da formação do sujeito.

A partir do momento em que profissionais da educação forem formados e instruídos para entender a necessidade de planejar o trabalho pedagógico, tendo em vista os conteúdos de gênero e sexualidade, a educação escolar ofertada às crianças estará cercada de mais possibilidades de construção identitária, livre de preconceitos ou desconhecimento. A importância da formação dos profissionais da educação, sobre as questões de gênero e sexualidade, se justifica, sobretudo devido à tarefa de educar que cabe à escola e, educar não só as crianças, mas direta ou indiretamente educar também a família, construindo significados que norteiam ações sociais. Ainda que seja comum o engessamento de discussões sobre gênero na escola, cabe a essa instituição criar condições de diálogo, buscando o enfrentamento e a superação de tabus, pois estes, muitas vezes, resultam da falta de informação e de comunicação. Do contrário a escola está sendo conivente com a escuridão posta sobre as temáticas de gênero, reproduzindo ativamente as condições de ignorância social sobre o tema. Enfrentar e conhecer entraves escolares para lidar com esse assunto, possivelmente é o primeiro passo para mudar esse cenário de escuridão e ignorância.

Dentre as dificuldades que se impõem aos agentes da escola, se encontra a de tratar essas questões com a família, visto que há certo receio em relação à maneira como a família receberia as ações sobre temáticas de gênero. Na aplicação da técnica de grupo focal com familiares de estudantes da escola e indagando-as sobre o que achavam de meninas e meninos não terem brincadeiras, atividades e cores 
separadas, as responsáveis presentes, expressaram suas opiniões e, em uníssono, concordaram com o discurso proferido por uma responsável que dizia:

Hoje em dia não tem mais isso não, minha menina brinca com vídeo game, jogos, às vezes não quer rosa. Então, hoje em dia está assim mesmo, eu acho que não tem problema não, porque eu quero mais que eles sejam livres. As escolhas dos brinquedos não vão influenciar na sexualidade da minha filha, eu vejo que ela é feminina, mesmo gostando de moto, de bola, isso não tem nada a ver (A.N., responsável por um aluno.)

Esse discurso denota uma aceitação das desconstruções dos fazeres e lugares exclusivamente reservados a meninos e meninas. Como também o entendimento de que ser feminina não significa estar presa em um mundo cor de rosa, com bonecas esguias e boas maneiras. Para tanto, em outro momento, as responsáveis pelas crianças afirmaram que a família necessita de mais informação para lidar com as questões que as crianças trazem para casa.

Assim, retorna-se à discussão sobre a necessária atuação política da escola em prol dos conteúdos de gênero. É urgente que ela se prepare e se abra ao diálogo com a família, trazendo à tona as questões sobre gênero. Ainda que uma pequena parcela tema encarar tais temáticas, a família vê a escola como o espaço dessa discussão, principalmente porque se sente desnorteada ao falar sobre o assunto, o que se explica posto que são pais e mães pertencentes a uma geração também imersa em tabus e desinformação, situação um pouco diferente da geração de seus filhos e filhas, que já tem maior acesso à informação, ainda que sejam pouco problematizadas.

Da investigação sobre os caminhos da educação escolar contemporânea, tendo em vista os desdobramentos e discussões de gênero que chegam à escola, sobretudo com relação às questões de feminilidades, ao evidenciar a necessidade de retirar estes temas da sombra dos tabus, ainda são encontradas diversas barreiras para desconstruí-los. Tais barreiras esbarram na formação docente, que não considerou adequadamente essas questões ou na desinformação de familiares e agentes escolares. Para evitar isso além do PCN, também nas Diretrizes Curriculares Nacionais para a Educação Básica (2010), é ressaltado que as temáticas de gênero devem ser trabalhadas:

Temas como saúde, sexualidade e gênero, vida familiar e social, assim como os direitos das crianças e adolescentes, de acordo com o Estatuto da Criança e do Adolescente (Lei $n^{\circ} 8.069 / 90$ ), preservação do meio ambiente, nos termos da política nacional de educação ambiental (Lei n] 9.795/99), educação para o consumo, educação fiscal, trabalho, ciência e tecnologia, e diversidade cultural devem permear o desenvolvimento dos conteúdos da 
base nacional comum e da parte diversificada do currículo. (DCN, 2010, p.115)

O gênero posto em questão na educação mobiliza diversas instâncias do social, pondo também a escola como lugar para fomento de alternativas pedagógicas distantes das práticas tradicionais que ditam o que é apropriado ao masculino e ao feminino, pois as concepções conservadoras e autoritárias, sobre gênero encontradas na escola, são também fruto de discursos gestados por ela mesma em seu cotidiano.

\section{CONSIDERAÇÕES FINAIS}

No processo de investigação foi possível perceber, que a permanência de certos padrões sexistas na escola põe-se em embate na contemporaneidade com certa perda de um referencial sexista que insistia em designar fazeres/coisas do masculino ou do feminino. No contexto do embate há, ainda, discursos mantenedores de posicionamentos sexistas, pode-se inferir, por exemplo, que sobre as meninas ainda é lançada uma visão angelical que considera um só tipo de feminilidade, aquele que as concebe numa redoma de doçura, passividade e "bom comportamento", traduzindo uma sujeição a um padrão tradicional e opressivo de ser menina. No entanto, também por meio dos discursos observou-se que as ideias sobre as meninas, não são apenas mantenedoras, ora são modificadoras, incorporando entendimentos de que não há uma única fórmula de feminilidade.

Por isso, há que se insistir numa educação preocupada com a equalização das relações de gênero, estendendo também aos meninos as mesmas desconstruções de uma masculinidade violenta, áspera, predatória do sexo oposto, que não pode ser sensível ou frágil. Fortalecendo outras experiências na construção das subjetividades e identidades de gênero dos sujeitos.

Há que se adotar em todos os espaços sociais envoltos em processos de subjetivação, uma atitude política preocupada com as questões de gênero, como um passo essencial na tentativa de democratizar espaços e construir uma sociedade plural. 


\title{
DISCUSSIONS ON GENDER AND FEMININITIES IN THE CONTEMPORARY SCHOOL
}

\begin{abstract}
:
In the face of the advances achieved by the feminist movements and the gender and sexuality studies, some understandings about being a woman have been moved, which it has enabled the deconstruction of limiting ideas in relation to feminine subjectivities. In contemporary times, we are constantly discussing women's rights, deconstructing gender stereotypes for girls and boys, fighting for gender equity. Therefore, it is desirable that new understandings on femininities should also be on the agenda of gender equity education from childhood. Thus, this article aims to problematize the persistence of sexist patterns in the school and the role of formal education in the deconstruction of them; chiefly by offering new understandings about feminine subjectivities and ways of being woman that are still limited to traditional stereotypes. In this sense, it uses discourse analysis to explore the construction of meanings. The results found are the need to improve teacher education on issues such as diversity and gender; the lack of training to several subjects in the school environment to deal with gender issues; the importance of open debates on gender and femininities as civic education for children, caregivers and subjects working in the school environment.
\end{abstract}

Keywords: Education. Gender. Subjectivities. Feminities. School.

\section{DISCUSIONES DE GÉNERO Y FEMENINIDADES EN LA ESCUELA CONTEMPORÁNEA}

\section{Resumen:}

Ante los avances logrados por la actuación de los movimientos feministas y por los estudios de género y sexualidad, se desplazaron algunos entendimientos conservadores sobre ser mujer, lo que posibilitó la deconstrucción de ideas limitantes en relación a las subjetividades femeninas. En la contemporaneidad constantemente se ve en pauta discusiones sobre derechos de las mujeres, deconstrucción de estereotipos de género para niñas y niños, lucha por equidad de género. Por lo tanto, es deseable que nuevos entendimientos sobre feminidades también estén en la pauta de una educación para la equidad de género desde la infancia. Así, este artículo tiene por objetivo problematizar la permanencia de patrones sexistas en la escuela y el papel de la educación en la deconstrucción de los mismos, evidenciando sobre todo las oportunidades de ofrecer a los sujetos nuevos entendimientos sobre subjetividades femeninas y modos de ser mujer que no se limite a los estereotipos tradicionales. Se utiliza el Análisis de Discurso como forma de explorar la construcción de sentidos. Preliminarmente, fueron identificados discursos progresistas y conservadores, en relación al debate de género y las cuestiones de las mujeres, coexistiendo y disputando espacio en el ambiente escolar. Al mismo tiempo, se observou el potencial de tales discursos en el fomento de subjetividades desde la más tierna infancia. Los resultados encontrados evidenciaron, a groso modo: la necesidad de mejorar la formación docente en temas como diversidad y género, la falta de preparación de diversos sujetos del ambiente escolar para lidiar con cuestiones de género, la importancia que espacios para debate sobre género y feminidades ejercen para la formación ciudadana de niños, responsables y sujetos que trabajan en el ambiente escolar.

Palabras clave: Educación. Género. Subjetividades. Femeninidades. Escuela. 


\section{REFERÊNCIAS}

BECKER, Howard Saul. Observação social e estudos de Caso Sociais IN: Métodos de pesquisa em ciências sociais. HUCITEC: São Paulo, 1997. Capítulo 5.

BUTLER, Judith. Fundamentos contingentes: o feminismo e a questão do "pósmodernismo". Cadernos Pagu. n.11, 1998, p.11-42.

BUTLER, Judith. Problemas de gênero: feminismo e subversão da identidade. Rio de Janeiro: Editora Civilização Brasileira. 2005.

BRASIL. Ministério da Educação. Resolução CNE/CNB n4, de 13 de julho de 2010. Diretrizes Curriculares Nacionais para Educação Básica, 2010. Disponível em: http://portal.mec.gov.br/index.php?option=com docman\&task=doc download\&gid=6

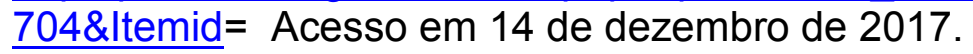

BRASIL. Ministério da Educação. Parâmetros Curriculares Nacionais - temas transversais- relações de gênero. Brasília: MEC/SEF. 1998. pp. 98-100.

CARVALHO, Marília Pinto de. Avaliação escolar, gênero e raça. Campinas, SP: Papirus. 2009.

DESLANDES, Suely Ferreira et al. (Org.) Pesquisa social: teoria, método e criatividade. Petrópolis, RJ: Vozes. 1994.

FISCHER, Rosa Maria Bueno. O dispositivo pedagógico da mídia: modos de educar na (e pela) TV. Revista Educação e Pesquisa, São Paulo, v.28, n.1, p. 151162, jan./jun. 2002

FOUCAULT, Michel. A arqueologia do saber. 8 ed. Rio de Janeiro: Forense, 2012.

GATTI, Bernadete Angelina. Grupo focal na pesquisa em ciências sociais e humanas. Ed. Liber livro: Brasília. 2005.

GOMÉZ, Pérez. As funções sociais da escola: da reprodução à reconstrução crítica do conhecimento e da experiência. In: SACRISTÁN, J. G. e GOMÉZ, P. Compreender e transformar o ensino. Porto Alegre: Artmed. 1998. pp.13-26.

HALL, Stuart. A Identidade cultural na pós-modernidade. São Paulo: DP\&A. 1997. 
LOURO, Guacira Lopes. Gênero, sexualidade e educação: uma perspectiva pósestruturalista. Petrópolis, RJ: Vozes, 1997.

MARIANO, Silvana Aparecida. O sujeito do feminismo e o pós-estruturalismo.

Estudos feministas. v.13, n.3, p.483-505, 2005.

MUCHEMBLED, Robert. O orgasmo e o ocidente: uma história do prazer do século XVI a nossos dias. São Paulo: WMF Martins Fontes. 2007.

PISCITELLI, Adriana. Gênero: a história de um conceito. In: Heloísa Buarque de Almeida; José Szwako. (Org.). Diferenças, igualdade. 1ed. São Paulo: Berlendis e Vertecchia Editores, 2009, v. 1, p. 116-150.

SCOTT, Joan Wallach. Gênero: uma categoria útil de análise histórica. Educação \& Realidade. Porto Alegre, vol. 20, n² 2, jul./dez. 1995, pp. 71-99.

SILVA, Tomaz Tadeu da. Documentos de identidade: uma introdução as teorias do currículo. 3. ed. Belo Horizonte: Autêntica. 2011. 